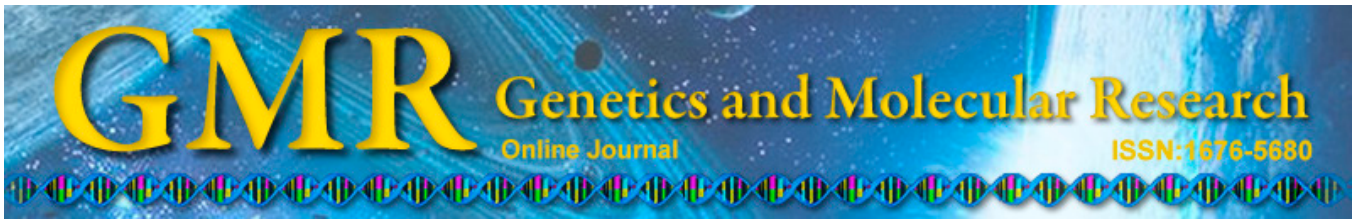

\title{
Development of simple sequence repeat markers in persimmon (Diospyros L.) and their potential use in related species
}

\author{
Y. Yang1*, Z.B. Jing ${ }^{2 *}$, X.F. Ruan ${ }^{1}$ and J.M. Cheng ${ }^{2}$ \\ ${ }^{1}$ College of Horticulture, Northwest A\&F University, Yangling, Shaanxi, China \\ ${ }^{2}$ College of Animal Science and Technology, Northwest A\&F University, \\ Yangling, Shaanxi, China \\ *These authors contributed equally to this study. \\ Corresponding author: X.F. Ruan \\ E-mail: xf.ruan@nwsuaf.edu.cn
}

Genet. Mol. Res. 14 (1): 609-618 (2015)

Received November 7, 2013

Accepted August 30, 2014

Published January 30, 2015

DOI http://dx.doi.org/10.4238/2015.January.30.2

\begin{abstract}
Persimmon (Diospyros L.) is an economically important fruit in the world, and it has been recognized as a healthy nutrient supply for human consumption. In this study, 14 microsatellite markers were developed from an AG/TC and AC/TG-enriched genomic library of Chinese persimmon Mopanshi. Twelve polymorphic markers were selected in 4 related species; these markers showed transferability to the 4 related persimmon species. In addition, 10 simple sequence repeat (SSR) markers were used to detect the genetic diversity among 51 persimmon accessions from China, Japan, and Korea. A total of 57 polymorphic bands with an average of 5.7 bands per primer pair were observed. According to cluster analysis and principal coordinate analysis, all persimmon accessions could be divided into 4 groups. A close relationship existed between $D$. kaki and D. oleifera, and D. glaucifolia and D. lotus. Jinzaoshi could be considered a separate
\end{abstract}


species of persimmon. These new SSR markers provide tools for evaluating genetic relatedness among different persimmon species.

Key words: Diospyros L.; Simple sequence repeat marker; Genetic diversity; Cluster analysis

\section{INTRODUCTION}

The genus of Diospyros (Ebenaceae) consists of about 400 species and is widely distributed from tropical to temperate regions of Asia, Africa, and Central-South America (Yonemori et al., 2000). Persimmon (Diospyros kaki Thunb.), which is native to China, is the most important species and is mainly cultivated in China, Japan, and Korea. Recently, this crop has become an alternative for fruit growers in Italy, Israel, and Spain. There are abundant persimmon germplasm resources in China. More than 900 accessions were collected and about 550 genotypes have been held in the National Field Genebank for Persimmon in Yangling, Shaanxi, China (Wang et al., 1997). Little is known about the infrageneric relationships within Diospyros, the genetic variation within the species, and mechanisms of evolution. Investigations that focus on their genetic variability could provide insight into their classification, conservation, utilization, and evolution.

Simple sequence repeats (SSRs) are highly polymorphic, codominant, easily reproducible, and often single-locus markers that are widely used for variability analysis and other applications in genetics and breeding. Recently, a set of 22 persimmon SSRs obtained from a CT/AG-repeat-enriched library was developed by Soriano et al. (2006), 9 SSR primers were developed in Japanese persimmon using inter-simple sequence repeat-polymerase chain reaction (ISSR-PCR) (Guo and Luo, 2006a), and 6 SSRs were isolated using amplified fragment length polymorphisms (AFLPs) of sequences containing repeats (Guo and Luo, 2008). However, there are fewer SSR markers for persimmon than other fruit trees.

The objectives of this study were to develop and identify SSR markers from Chinese persimmon and to evaluate the genetic diversity of persimmons that originated from China, Japan, and Korea. Our study will facilitate the efficient evaluation, conservation, and utilization of Chinese persimmon germplasm resources.

\section{MATERIAL AND METHODS}

\section{Plant materials}

The Chinese local variety Mopanshi was used to develop polymorphic microsatellite loci. Four species: date-plum (D. lotus L.), Chekiang persimmon (D. glaucifolia Metc.), oily persimmon (D. oleifera Cheng.), and Jinzaoshi (Diospyros sp) were used to evaluate the polymorphism and transferability of developmental microsatellite loci. Fifty-one genotypes of persimmon (Diospyros L.) were selected to evaluate the universality of primers (Table 1). These genotypes, which belong to the C-PCNA (China, pollination-constant non-astringent), J-PCNA (Japan, pollination-constant non-astringent), and PCA (pollination-constant astringent) types, were selected from 14 different provinces of China, Japan, and Korea. Among them, 43 genotypes were $D$. kaki Thunb. The different genotypes showed rich diversity in traits including fruit size, color, shape, and texture. 
Table 1. List of materials used in this study.

\begin{tabular}{|c|c|c|c|c|}
\hline Code & Accession name & Species & Type & Origin \\
\hline 1 & Louhe & D. kaki Thunb. & PCA & Shanxi, China \\
\hline 2 & Jiuyueqing & D. kaki Thunb. & PCA & Henan, China \\
\hline 3 & Yuanxiaoshi & D. kaki Thunb. & PCA & Fujian, China \\
\hline 4 & Heze Bayuehuang & D. kaki Thunb. & PCA & Shandong, China \\
\hline 5 & Huaitaishi & D. kaki Thunb. & PCA & Shaanxi, China \\
\hline 6 & Laoshigou & D. kaki Thunb. & PCA & Henan, China \\
\hline 7 & Shengdishi & D. kaki Thunb. & PCA & Shaanxi, China \\
\hline 8 & Mopanshi & D. kaki Thunb. & PCA & Hebei, China \\
\hline 9 & Dayeshushi & D. kaki Thunb. & PCA & Henan, China \\
\hline 10 & Changanmiandanshi & D. kaki Thunb. & PCA & Shaanxi, China \\
\hline 11 & Laopige & D. kaki Thunb. & PCA & Henan, China \\
\hline 12 & Hangzhou Niuxinshi & D. kaki Thunb. & PCA & Zhejiang, China \\
\hline 13 & Licheng Fangshi & D. kaki Thunb. & PCA & Shanxi, China \\
\hline 14 & Jinshi & D. kaki Thunb. & PCA & Shanxi, China \\
\hline 15 & Ehuangshi & D. kaki Thunb. & PCA & Anhui, China \\
\hline 16 & Heixinshi & D. kaki Thunb. & PCA & Shaanxi, China \\
\hline 17 & Licheng Mianshi & D. kaki Thunb. & PCA & Shanxi, China \\
\hline 18 & Mianrangshi & D. kaki Thunb. & PCA & Hebei, China \\
\hline 19 & Sanyuan Shaoshi & D. kaki Thunb. & PCA & Shaanxi, China \\
\hline 20 & Xiaogaishi & D. kaki Thunb. & PCA & Henan, China \\
\hline 21 & Qujing Shuishi & D. kaki Thunb. & PCA & Yunnan, China \\
\hline 22 & Guangzhou Dahongshi & D. kaki Thunb. & PCA & Guangdong, China \\
\hline 23 & Gongcheng Shuishi & D. kaki Thunb. & PCA & Guangxi, China \\
\hline 24 & Zhejiang Yeshi & D. kaki Thunb. & PCA & Zhejing, China \\
\hline 25 & Gongcheng Niuxinshi & D. kaki Thunb. & PCA & Guangxi, China \\
\hline 26 & Anxi Youshi & D. kaki Thunb. & PCA & Fujian, China \\
\hline 27 & Guanguanshi & D. kaki Thunb. & PCA & Hubei, China \\
\hline 28 & Zhouquhuoshi & D. kaki Thunb. & PCA & Gansu, China \\
\hline 29 & Heratanenashi & D. kaki Thunb. & PVA & Japan \\
\hline 30 & Luotian Tianshi & D. kaki Thunb. & PCNA & Hubei, China \\
\hline 31 & Tianbaogai & D. kaki Thunb. & PCNA & Hubei, China \\
\hline 32 & Qiuyan & D. kaki Thunb. & PCNA & Hubei, China \\
\hline 33 & Xiaoguotianshi & D. kaki Thunb. & PCNA & Hubei, China \\
\hline 34 & Taiwan Zhengshi & D. kaki Thunb. & PCA & Taiwan, China \\
\hline 35 & Changzunshi & D. kaki Thunb. & PCA & Korea \\
\hline 36 & Shagu-01 & D. kaki Thunb. & PCA & Korea \\
\hline 37 & Jiro & D. kaki Thunb. & PCNA & Japan \\
\hline 38 & Fuyu & D. kaki Thunb. & PCNA & Japan \\
\hline 39 & Yohou & D. kaki Thunb. & PCNA & Japan \\
\hline 40 & Shiyangshi & D. kaki Thunb. & PCA & Henan, China \\
\hline 41 & Xiangyang Niuxinshi & D. kaki Thunb. & PCA & Hubei, China \\
\hline 42 & Hybrid No.1 & D. kaki Thunb. & PCA & NPGR, China \\
\hline 43 & Hybrid No.2 & D. kaki Thunb. & PCA & NPGR, China \\
\hline 44 & Oily persimmon-01 & D. oleifera Cheng & -- & Zhejiang, China \\
\hline 45 & Oily persimmon- 02 & D. oleifera Cheng & -- & Zhejiang, China \\
\hline 46 & Chekiang persimmon (M) & D. glaucifolia Metc. & -- & Zhejiang, China \\
\hline 47 & Chekiang persimmon (F) & D. glaucifolia Metc. & -- & Zhejiang, China \\
\hline 48 & Date plum-01 & D. lotus L. & -- & Shaanxi,China \\
\hline 49 & Date plum-02 & D. lotus L. & -- & Shaanxi,China \\
\hline 50 & Date plum-03 & D. lotus L. & -- & Shaanxi,China \\
\hline 51 & Jinzaoshi & Diospyros sp & -- & Zhejiang, China \\
\hline
\end{tabular}

Pollination-constant non-astringent (PCNA), pollination-constant astringent (PCA).

\section{SSR marker development}

Fourteen SSR markers were developed from a library enriched for AG/TC and AC/ TG motifs and constructed with genomic DNA from the Chinese local variety Mopanshi using the method based on biotinylated oligonucleotide sequences bound to streptavidin-coated magnetic beads that was described by Gao et al. (2003) with some modifications. Genomic 
DNA was digested with EcoRI and MseI restriction enzymes. The cloning of the PCR products was carried out by using the pGEM-T ${ }^{\circledR}$ Easy Vector Kit (Promega, USA). Recombinant plasmids were identified by means of blue-white screening. After colony PCR selection with plasmid primers $\mathrm{SP}_{6}$ and $\mathrm{T}_{7}$, inserts with 200-500 bp were sequenced using an ABI PRISM 377 DNA sequencer (Applied Biosystems, USA) and the BigDye Terminator version 1.1 Cycle Sequencing Kit (Applied Biosystems). Sequences were analyzed by Clone Manager 7 software (Version 7.04, Sci Ed Central, USA). Primer pairs were designed from the regions flanking the microsatellite to be $18-25$ bp long with an annealing temperature between 45 and $65^{\circ} \mathrm{C}$ (optimum $55^{\circ} \mathrm{C}$ ) and have an expected product size of $100-300 \mathrm{bp}$ using the program Primer Designer 5 (version 5.04, Sci Ed Central).

\section{SSR analysis}

For genotyping, genomic DNA was extracted and tested from silica-dried young leaves by the cetyltrimethylammonium bromide method (Jing et al., 2013). PCRs were carried out in a total volume of $25 \mu \mathrm{L}$ containing $50 \mathrm{ng}$ DNA, $0.2 \mathrm{mM}$ dNTPs, $5 \mathrm{pM}$ primer, 2 $\mathrm{mM} \mathrm{Mg}{ }^{2+}, 1 \mathrm{U}$ Taq DNA polymerase (Qiagen, USA), and 1X Taq Buffer (10 mM Tris-HCl, $\mathrm{pH} 8.3,50 \mathrm{mM} \mathrm{KCl}$ ). The annealing temperature for each primer pair was optimized using a Mastercycler ${ }^{\circledR}$ ep gradient (Eppendorf, Germany), and the PCR products were checked by electrophoresis on a $2 \%$ agarose gel. To evaluate polymorphic loci using optimized annealing temperatures, a GeneAmp PCR system 9700 thermal cycler (Perkin Elmer, USA) was used. Cycling conditions were as follows: initial denaturation at $94^{\circ} \mathrm{C}$ for $5 \mathrm{~min} ; 30$ cycles at $94^{\circ} \mathrm{C}$ for $45 \mathrm{~s}$, the primer-specific annealing temperature (Table 2) for $45 \mathrm{~s}$, and $72^{\circ} \mathrm{C}$ for $90 \mathrm{~s}$; and

Table 2. Characterization of the 14 microsatellite loci indentified in Diospyros variety Mopanshi.

\begin{tabular}{|c|c|c|c|c|c|}
\hline Locus & Primer sequence $\left(5^{\prime}-3^{\prime}\right)$ & Repeat motif & $\mathrm{Ta}\left({ }^{\circ} \mathrm{C}\right)$ & Size (bp)* & GenBank accession No. \\
\hline mDP01 & $\begin{array}{l}\text { F: TGATTACACACGCCCACACT } \\
\text { R: CCTCCACCTTTTGCTCTCTG }\end{array}$ & $(\mathrm{GA})_{21}$ & 57 & 174 & EF567396 \\
\hline mDP06 & $\begin{array}{l}\text { F: CAGACATACAAAGGGGCCTAA } \\
\text { R: TTCCTCAAATTCCTTTGCAC }\end{array}$ & $\mathrm{A}_{15}-(\mathrm{GA})_{19}$ & 55 & 141 & EF567401 \\
\hline mDP07 & $\begin{array}{l}\text { F: TAGGAACTCTGATTCTTTTGCTTAC } \\
\text { R: TTTCACGGGAGATGGAGAC }\end{array}$ & $(\mathrm{TC})_{15}(\mathrm{AC})_{14}$ & 52 & 291 & EF567402 \\
\hline mDP08 & $\begin{array}{l}\text { F: TGTCCTCAACCTACATAAG } \\
\text { R: GGTCTATACAAGAGCTGTATC }\end{array}$ & $(\mathrm{TC})_{13}(\mathrm{CA})_{20}$ & 52 & 292 & EF567403 \\
\hline mDP09 & $\begin{array}{l}\text { F: ACCGGCAGACAAATTCAATC } \\
\text { R: CCATAGGCATTGCTTCCATT }\end{array}$ & $(\mathrm{GA})_{12}-(\mathrm{GA})_{3}-(\mathrm{GA})_{3}$ & 55 & 116 & EF567404 \\
\hline mDP11 & $\begin{array}{l}\text { F: TCGCTAGCTTCATAAAAATGTTG } \\
\text { R: GGTCTGGATTCGCCATTAGA }\end{array}$ & $\left(\mathrm{A}_{10} \mathrm{G}\right)_{2}$ & 58 & 230 & EF567405 \\
\hline mDP13 & $\begin{array}{l}\text { F: ATGACGACAAGCCAGTTTGG } \\
\text { R: TTGCTTGTTCTGGTTGGTTG }\end{array}$ & $(\mathrm{TG})_{17}$ & 55 & 250 & EF567406 \\
\hline mDP15 & $\begin{array}{l}\text { F: ACAACCCTTCTTTTATAC } \\
\text { R: ATCCAGGAGGGCAAAGAACT }\end{array}$ & $(\mathrm{AC})_{13}(\mathrm{AT})_{4}$ & 50 & 116 & EF567408 \\
\hline mDP16 & $\begin{array}{l}\text { F: CTACTTCCACATAGCATCAC } \\
\text { R: GTAAAGATTCATAAAACCTAG }\end{array}$ & $(\mathrm{TG})_{10}$ & 55 & 140 & EF567409 \\
\hline mDP17 & $\begin{array}{l}\text { F: CCAAATCATTCGAAGCCAAT } \\
\text { R: CCTTCACCGATGTCCTTTGT }\end{array}$ & $(\mathrm{GA})_{21}$ & 53 & 138 & EF567410 \\
\hline mDP18 & $\begin{array}{l}\text { F: TACTACTGATCTACCAAGTC } \\
\text { R: GGATCAGAAGCCCAGTTCAA }\end{array}$ & $(\mathrm{GA})_{17}$ & 55 & 252 & EF567411 \\
\hline mDP19 & $\begin{array}{l}\text { F: CAATCTCACATAGTAGGATTAAGGA } \\
\text { R: TGACTATGGGGGTCCACTTC }\end{array}$ & $(\mathrm{AT})_{4}(\mathrm{GTAT})_{2}(\mathrm{AT})_{2}$ & 48 & 261 & EF567412 \\
\hline mDP20 & $\begin{array}{l}\text { F: AGAAGACCCAGACCAGAGAAG } \\
\text { R: GGCCACCAAATCAACCATACC }\end{array}$ & $(\mathrm{GA})_{17}$ & 57 & 204 & EF567413 \\
\hline mDP21 & $\begin{array}{l}\text { F: ACCGGCAGACAAATTCAATC } \\
\text { R: AGTCGATGGATGAGGAAAGC }\end{array}$ & $(\mathrm{GA})_{8}-(\mathrm{GA})_{8}$ & 55 & 215 & EF567414 \\
\hline
\end{tabular}

*Length is calculated from the sequenced clone. 
$72^{\circ} \mathrm{C}$ for $7 \mathrm{~min}$. PCR products were separated by electrophoresis on denaturing $6 \%$ polyacrylamide gels and visualized by silver staining. The molecular size of the amplified fragments was estimated using a 10-bp ladder (Invitrogen, USA).

\section{Data analysis}

The power of discrimination $(P D)$ was defined as $P D=1-\sum \mathrm{g}_{\mathrm{i}}^{2}$, where $\mathrm{g}_{\mathrm{i}}$ is the frequency of the ith genotype (Kloosterman et al., 1993). Each SSR fragment was scored as present (1) or absent (0) for each of the 51 DNA samples excluding the weak and blurred bands, thus generating a binary data matrix. A locus was considered polymorphic if more than one band was detected by the same primers in all individuals (Jing and Wang, 2013). The binary data matrix was analyzed using the NTSYS-pc version 2.1e software package (Rohlf, 2000). The pairwise genetic distances among all cultivars according to Nei (1978) were calculated based on Jaccard's similarity coefficient. Cluster analysis was performed using the unweighted pair-group method with arithmetic average (UPGMA). The dendrogram was constructed using the NTSYS-pc version 2.1 software package (Rohlf, 2000).

\section{RESULTS}

\section{Evaluation of SSR markers}

Twelve primer pairs were used to investigate the transferability of the primers and polymorphism in 4 related species: date-plum (D. lotus L.), Chekiang persimmon (D. glaucifolia Metc.), oily persimmon (D. oleifera Cheng.), and Jinzaoshi (Diospyros $\mathrm{sp}$ ). Locus characteristics, primer sequences, and GenBank accession numbers of $14 \mathrm{mi}-$ crosatellite loci are listed in Table 2, and the genetic parameters of the 12 microsatellites that were evaluated in 4 Diospyros spp are summarized in Table 3. All 12 loci were polymorphic in the 4 Diospyros spp, and each locus had 4 to 8 alleles. The observed $\left(H_{\mathrm{O}}\right)$ and expected $\left(H_{\mathrm{E}}\right)$ heterozygosity at each locus ranged from 0.09 to 0.97 (average 0.77 ) and 0.45 to 0.87 (average 0.68 ), respectively. The PD ranged from 0.16 to 0.92 , with an average value of 0.61 .

\section{Table 3. The genetic parameters determined in 4 species with 12 microsatellite loci.}

\begin{tabular}{|c|c|c|c|c|c|c|c|c|}
\hline Locus & $\mathrm{A}^{*}$ & $H_{\mathrm{O}}$ & $H_{\mathrm{E}}$ & $\mathrm{PD}$ & Date plum & Chekiang persimmon & Oily persimmon & Jinzaoshi \\
\hline $\mathrm{mDP} 01$ & 5 & 0.94 & 0.53 & 0.75 & $153-174$ & $153-174$ & $153-174$ & $153-185$ \\
\hline mDP08 & 3 & 0.61 & 0.49 & 0.54 & 325 & & $290-325$ & $300-325$ \\
\hline mDP09 & 5 & 0.97 & 0.45 & 0.62 & $117-127$ & $117-127$ & $111-127$ & 117 \\
\hline mDP11 & 5 & 0.60 & 0.85 & 0.77 & 242 & 242 & $228-242$ & 228 \\
\hline mDP13 & 5 & 0.94 & 0.59 & 0.31 & $248-253$ & $248-253$ & $250-255$ & $248-253$ \\
\hline mDP15 & 7 & 0.71 & 0.87 & 0.92 & 84-119 & 84-119 & $114-124$ & $119-124$ \\
\hline mDP16 & 4 & 0.09 & 0.66 & 0.16 & 140 & 140 & $130-140$ & 140 \\
\hline mDP17 & 7 & 0.89 & 0.79 & 0.69 & $138-144$ & 138 & $135-150$ & 135 \\
\hline mDP18 & 8 & 0.91 & 0.78 & 0.81 & $232-268$ & $232-260$ & $232-252$ & $232-250$ \\
\hline mDP19 & 4 & 0.69 & 0.56 & 0.57 & $260-270$ & $260-280$ & $260-320$ & $260-320$ \\
\hline mDP20 & 5 & 0.83 & 0.77 & 0.89 & $210-225$ & $205-210$ & 210 & $205-220$ \\
\hline mDP21 & 8 & 0.94 & 0.68 & 0.52 & $216-241$ & $216-241$ & $216-241$ & $216-241$ \\
\hline
\end{tabular}

$\mathrm{A}^{*}=$ number of alleles per locus; $H_{\mathrm{O}}=$ observed heterozygosity; $H_{\mathrm{E}}=$ expected heterozygosity; PD = power of discrimination; numbers and ranges listed below each species indicate the locus size (in bp). 


\section{Polymorphism of the SSR markers}

In this study, 10 SSR markers were used to evaluate the genetic diversity of 51 persimmon accessions. A total of 59 bands were amplified ranging in size from 84 to $320 \mathrm{bp}$, and 57 $(96.25 \%$ ) bands were polymorphic (Table 4$)$. Each primer pair generated 4 to 8 bands with an average of 5.9 bands per primer pair, and the percentage of polymorphic bands produced by each primer ranged from 75 to $100 \%$.

\begin{tabular}{|c|c|c|c|}
\hline Primer & $t$ & $p$ & $\mathrm{P} \%$ \\
\hline mDP01 & 5 & 5 & 100 \\
\hline mDP09 & 5 & 5 & 100 \\
\hline mDP11 & 5 & 5 & 100 \\
\hline mDP13 & 5 & 5 & 100 \\
\hline mDP15 & 7 & 7 & 100 \\
\hline mDP16 & 4 & 3 & 75 \\
\hline mDP17 & 8 & 8 & 100 \\
\hline mDP18 & 8 & 8 & 100 \\
\hline mDP19 & 4 & 4 & 100 \\
\hline mDP21 & 8 & 7 & 87.5 \\
\hline Total & 59 & 57 & 962.5 \\
\hline Average & 5.9 & 5.7 & 96.25 \\
\hline
\end{tabular}

$t=$ number of total loci; $p=$ number of polymorphic loci; $\mathrm{P} \%=$ percentage of polymorphic loci.

\section{Cluster analysis}

The pairwise genetic similarity value was calculated using Jaccard's coefficient to assess the genetic distance among 51 persimmon accessions. The Jaccard's coefficient of similarity value ranged from 0.38 to 0.86 , which indicated that a relative high level of genetic diversity existed among these persimmons.

Cluster analysis by the UPGMA was used to construct the dendrogram based on Nei's genetic distance. The results showed that all persimmon accessions could be divided into 4 major clusters at the similarity level of 0.508 (Figure 1). Cluster 1 consisted of Louhe, Yuanxiaoshi, Laoshigou, Dayeshushi, Licheng Mianshi, and Sanyuan shaoshi (D. kaki). Cluster 2 included Oily persimmon-01, Oily persimmon-02 (D. oleifera), and 37 other persimmon accessions of D. kaki. Cluster 3 was composed of Chekiang persimmon (M), Chekiang persimmon (F) (D. glaucifolia), Date plum-01, Date plum-02, and Date plum-03 (D. lotus). Cluster 4 only included Jinzaoshi (Diospyros sp).

\section{Principal component analysis}

Principal coordinate analysis (PCoA) further helped to describe the variability among these accessions in a 2-dimensional mode (Jing et al., 2013). PCoA was completed using the genetic similarity matrix and aimed to better understand the relationships between the accessions (Figure 2). As shown in Figure 1, the classification of different persimmon accessions derived from PCoA was similar to the classifications by UPGMA analysis. Groups 1-4 of the PCoA-based dendrogram corresponded to Clusters 1-4 in the UPGMA-based dendrogram. These results showed that D. oleifera, D. glaucifolia, D. lotus, and Jinzaoshi (Diospyros sp) were distinctly differentiated. 


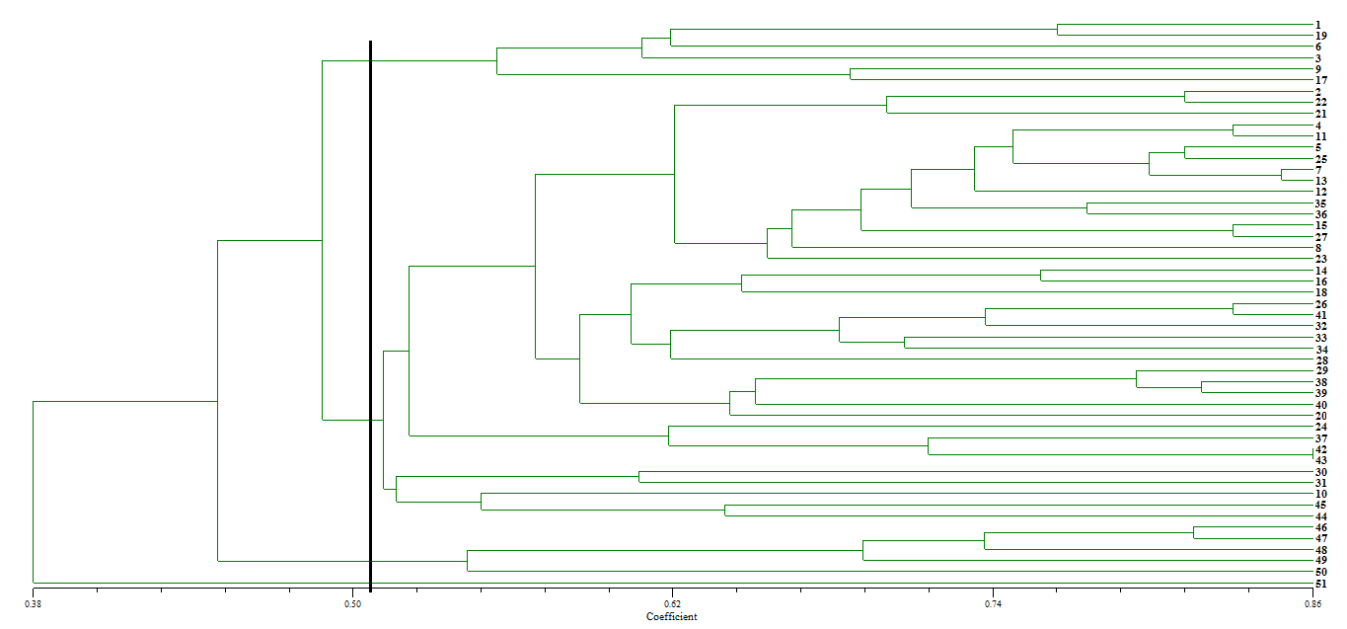

Figure. 1. Dendrogram showing relationships among different persimmon accessions using unweighted pair group method with arithmetic average (UPGMA) analysis. The accession numbers are listed in Table 1.

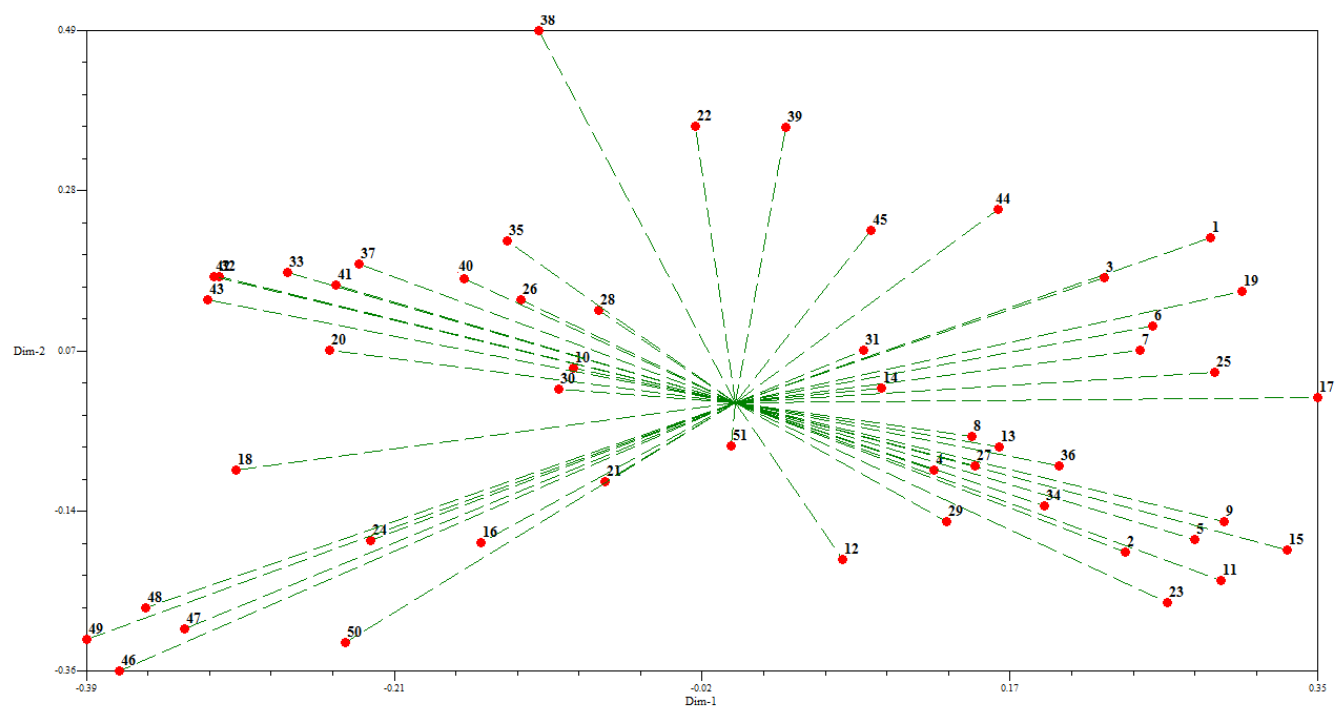

Figure. 2. Two-dimensional plot of the principal component analysis of 51 persimmon accessions based on 10 simple sequence repeat (SSR) markers along the first two principal axes.

\section{DISCUSSION}

Recently, some molecular markers were used to analyze the genetic diversity of persimmon species; these markers included random amplification of polymorphic DNA, restriction fragment length polymorphism, AFLP, sequence-related amplified polymorphism (SRAP), inter-retrotransposon amplified polymorphism, and retrotransposon-microsatellite amplified polymorphism markers (Luo et al., 1995; Kanzaki et al., 2000; Maki et al., 2001; Badenes et al., 2003; Yamagishi et al., 2005; Guo and Luo, 2006a; Guo et al., 2006; Yonemori 
et al., 2008a,b; Jing et al., 2013). Among the different molecular markers, SSRs, which are also called microsatellites, are the best-suited markers for genotyping the Diospyros genus (Luo et al., 2013). Guo and Luo (2006a, 2008, 2011) reported several SSR markers by ISSRsuppression PCR. Soriano et al. (2006) developed 22 SSRs using a CT/AG-repeat-enriched library. However, SSR markers of persimmon were not updated. In this study, 14 SSR markers were developed from the Chinese local variety Mopanshi. All loci except mDP16 showed high levels of heterozygosity and high PD values in the set of individuals that were tested. One hundred percent of these markers produced PCR products of the expected size with polymorphisms in 4 tested Diospyros species, indicating their high level of transferability to other Diospyros species. Therefore, these SSR markers may be useful to study the genetic diversity in Diospyros.

Persimmon has existed for 10,000 years in China (Jing et al., 2013). In addition, Japanese persimmon (or Oriental persimmon) is reported to have originated in China (Yakushiji and Nakatsuka, 2007). Today, more than 900 accessions of persimmon were collected in the National Field Genebank for Persimmon in China. The genesis basis of persimmon and genetic relationships of some species have some controversy and confusion. Thus, 10 developed SSR markers were used to evaluate the genetic diversity among some Chinese, Korean, and Japanese wild persimmon species. In this study, the $96.25 \%$ of markers were polymorphic, which is a higher value than those reported in previous studies using SSRs and other markers. For example, Guo and Luo (2006b) reported that the polymorphic percentage of 27 genotypes was $80.88 \%$ using SRAP markers. Luo et al. (2013) concluded that the polymorphic percentage of 20 genotypes of persimmon was $94.87 \%$ based on targeted region amplified polymorphism markers. Naval et al. (2010) found that the polymorphic percentage of 71 persimmon cultivars was $74 \%$ by SSR markers. Soriano et al. (2006) reported that 22 SSR markers generated 2 to 8 alleles per locus (average 5.14) in 12 persimmon cultivars. In contrast, our polymorphism rates were higher, and each primer pair generated 4 to 8 bands per locus (average 5.9). Our results showed that SSR markers displayed rich polymorphism in Chinese persimmon. The polymorphism levels in this study also suggest that SSR markers are a reliable and effective tool to analyze the genetic diversity of persimmon and that a high level of genetic diversity existed among Chinese persimmon species.

In this study, the 51 persimmon accessions were divided into 4 major clusters at the similarity level of 0.508 . Cluster 1 consisted of 6 genotypes of D. kaki that included Louhe, Yuanxiaoshi, Laoshigou, Dayeshushi, Licheng Mianshi, and Sanyuan shaoshi, and these genotypes originated from different provinces. However, a close relationship was found among these 6 genotypes of $D$. kaki, which suggested that the individual plants are genetically similar. This clustering result agreed with their morphological characteristics. In cluster 2, Korean, Japanese, and Chinese native persimmons were clustered together. Among them, Changanmiandanshi, Luotian Tianshi, and Tianbaogai, which originated from China, were clustered with two genotypes of $D$. oleifera. This indicated that they may be closely related. In addition, Hybrid No.1 and Hybrid No.2 were the hybrid offspring from Jiro; thus, they were clustered together. Jing et al. (2013) found that a close relationship existed between D. glaucifolia and $D$. lotus using SRAP analysis. In this study, 2 genotypes of D. glaucifolia and 3 genotypes of $D$. lotus were clustered together, which supported the previous results. Whether Jinzaoshi is a subspecies of another species or a separate species of persimmon is still disputable (Jing et al., 2013). In this study, a large distance was found between Jinzaoshi (Diospyros sp) and other species, further supporting the view by Jing et al. (2013) that Jinzaoshi is a separate species. 
In this study, 14 new SSR markers were developed from Chinese persimmon species, and our results showed that these SSR markers have good universality in different persimmon species. They could be used to analyze the genetic relationships among persimmon species. Some of the important aims of breeding practices for persimmon are to increase the yield and fruit quality. The identification of persimmon with high genetic diversity becomes a goal of many breeding programs that aim to explore the heterosis. It is essential for breeders using Chinese persimmons as parents to take full advantage of heterosis to delineate the interspecific and intraspecific relationships between Chinese wild types and cultivars that come from other countries.

\section{ACKNOWLEDGMENTS}

Research supported by a Project for Crop Germplasm Conservation grant from the China Agriculture Ministry (\#NB2012-2130135-21) and a Special Fund for Agro-scientific Research in the Public Interest (\#201203047).

\section{REFERENCES}

Badenes ML, Garcés A, Romero C, Romero M, et al. (2003). Genetic diversity of introduced and local Spanish persimmon cultivars revealed by RAPD markers. Genet. Res. Crop Evol. 50: 579-585.

Gao GQ, He GH and Li YR (2003). Microsatellite enrichment from AFLP fragments by magnetic beads. Acta Bot. Sin. 45: $1266-1269$

Guo DL and Luo ZR (2006a). Development of SSR primers using ISSR-PCR in Diospyros kaki Thunb. Mol. Ecol. Notes 6: $886-887$.

Guo DL and Luo ZR (2006b). Genetic relationships of some PCNA persimmons (Diospyros kaki Thunb.) from China and Japan revealed by SRAP analysis. Genet. Res. Crop Evol. 53: 1597-1603.

Guo DL and Luo ZR (2008). Microsatellite isolation and characterization in Japanese persimmon (Diospyros kaki). Biochem. Genet. 46: 323-328.

Guo DL and Luo ZR (2011). Genetic relationships of the Japanese persimmon Diospyros kaki (Ebenaceae) and related species revealed by SSR analysis. Genet. Mol. Res. 10: 1060-1068.

Guo DL, Zhang HQ and Luo ZR (2006). Genetic relationships of Diospyros kaki Thunb. and related species revealed by IRAP and REMAP analysis. Plant Sci. 170: 528-533.

Jing ZB and Wang XP (2013). Genetic relationship between Chinese wild Vitis species and American and European cultivars based on ISSR markers. Biochem. Syst. Ecol. 46: 120-126.

Jing ZB, Ruan XF, Wang RZ and Yang Y (2013). Genetic diversity and relationships between and within persimmon (Diospyros L.) wild species and cultivated varieties by SRAP markers. Plant Syst. Evol. 299: 1485-1492.

Kanzaki S, Yonemori K, Sato A, Yamada M, et al. (2000). Analysis of the genetic relationships among pollinationconstant and non-astringent (PCNA) cultivars of persimmon (Diospyros kaki Thunb.) from Japan and China using amplified fragment length polymorphism (AFLP). J. Jpn. Soc. Hort. Sci. 69: 665-670.

Kloosterman AD, Budowle B and Daselaar P (1993). PCR-amplification and detection of the human D1S80 VNTR locus. Amplification conditions, population genetics and application in forensic analysis. Int. J. Legal Med. 105: 257-264.

Luo C, Zhang F, Zhang QL, Guo DY, et al. (2013). Characterization and comparison of EST-SSR and TRAP markers for genetic analysis of the Japanese persimmon Diospyros kaki. Genet. Mol. Res. 12: 2841-2851.

Luo ZR, Yonemori K and Sugiura A (1995). Evaluation of RAPD analysis for cultivar identification of persimmons. $J$. Jpn. Soc. Hort. Sci. 64: 535-541.

Maki S, Oyama K, Kurahashi T, Nakahira T, et al. (2001). RFLP analysis for cultivar identification of persimmons. Sci. Hortic. 91: 407-412.

Naval MM, Zuriaga E, Pecchioli S, Llácer G, et al. (2010). Analysis of genetic diversity among persimmon cultivars using microsatellite markers. Tree Genet. Genomes 6: 677-687.

Nei M (1978). Estimation of average heterozygosity and genetic distance from a small number of individuals. Genetics 89: $583-590$.

Rohlf FJ (2000). NTSYS-pc: numerical taxonomy and multivariate analysis system. Version 2.1. Exeter Software, Setauket. 
Soriano JM, Pecchioli S, Romero C, Vilanova S, et al. (2006). Development of microsatellite markers in polyploid persimmon (Diospyros kaki Lf) from an enriched genomic library. Mol. Ecol. Notes 6: 368-370.

Wang RZ, Yang Y and Li GC (1997). Chinese persimmon germplasm resources. Acta Hortic. 436: 43-50.

Yakushiji H and Nakatsuka A (2007). Recent persimmon research in Japan. Jpn. J. Plant Sci. 1: 42-62.

Yamagishi M, Matsumoto S, Nakatsuka A and Itamura H (2005). Identification of persimmon (Diospyros kaki) cultivars and phenetic relationships between Diospyros species by more effective RAPD analysis. Sci. Hortic. 105: 283-290.

Yonemori K, Sugiura A and Yamada M (2000). Persimmon genetics and breeding. Plant Breed. Rev. 19: 191-225.

Yonemori K, Honsho C, Kitajima A, Aradhya M, et al. (2008a). Relationship of European persimmon (Diospyros kaki Thunb.) cultivars to Asian cultivars, characterized using AFLPs. Genet. Resour. Crop Ev. 55: 81-89.

Yonemori K, Kanzaki S, Honsho C, Akagi T, et al. (2008b). Phylogeny and cultivar development of Diospyrus kaki: a survey based on molecular analysis. Adv. Hort. Sci. 22: 261-268. 